\title{
O pré-condicionamento com solução salina hipertônica reduz o stress oxidativo na isquemia reperfusão hepática com hipotermia
}

\author{
Mariana da Silva Villas Boas ${ }^{1}$, Estela Regina Ramos Figueira ${ }^{2}$, \\ Joel Avancini Rocha Filho², Luiz Augusto Carneiro D’Albuquerque ${ }^{2}$
}

Boas MSV, Figueira ERR, Rocha Filho JA, D’Albuquerque LAC. O pré-condicionamento com solução salina hipertônica reduz o stress oxidativo na isquemia reperfusão hepática com hipotermia. Rev Med (São Paulo). 2015 jan.-mar.;94(1):68-9.

\section{INTRODUÇ̃̃O}

A lesão isquemia/reperfusão (IR) hepática desencadeia uma reação inflamatória que influencia diretamente na sobrevivência do enxerto após o transplante de fígado. A hipotermia reduz drasticamente a lesão IR, sendo a base da preservação dos órgãos. No entanto, outras estratégias são necessárias para aumentar a viabilidade do enxerto. Em trabalho anterior realizado no nosso LIM, foi demonstrado que a solução salina hipertônica(SSH) reduz a lesão hepática após a IR hepática normotérmica.

O objetivo deste estudo foi avaliar os efeitos do condicionamento do fígado com SSH na IR hepática com hipotermia tópica do fígado.

\section{MÉTODOS} grupos:

Cinquenta ratos Wistar foram divididos em 5

I) Grupo Sham, animais foram submetidos a ressecção dos lobos hepáticos direito e caudado sem que o fígado sofresse isquemia;

II) Grupo Controle de Isquemia Quente ou Normotérmica (Quente),os animais foram submetidos a oclusão do pedículo dos lobos mediano e lateral esquerdo do fígado, sendo produzida isquemia isquemia normotérmica de aproximadamente $70 \%$ do fígado por 40 min, e imediatamente após reperfusão do fígado, os lobos direito e caudado não isquemiados foram ressecados;

III) Grupo Controle de Isquemia Fria (Fria),animais foram submetidos a $40 \mathrm{~min}$ de isquemia parcial do fígado resfriado a $10^{\circ} \mathrm{C}$, seguido de ressecção dos lobos não isquemiados no início da reperfusão;

VI) Grupo Fria+SSH pré-reperfusão (Fria-PR), animais submetidos a $40 \mathrm{~min}$ de isquemia fria do fígado tratados com injeção intravenosa de $\mathrm{NaCl} 7,5 \%$ (SSH), $4 \mathrm{~mL} / \mathrm{kg}, 10 \mathrm{~min}$ antes da reperfusão, sendo realizada ressecção dos lobos não isquemiados no início da reperfusão;

V) Grupo Fria+SSH pré-isquemia (Fria-PI), animais tratados com injeção intravenosa de $\mathrm{NaCl} 7,5 \%$ (SSH), $4 \mathrm{~mL} / \mathrm{kg}, 10$ minutos antes da indução isquêmica, submetidos a 40 min de isquemia hepática fria, com ressecção dos lobos hepáticos não isquemiados no início da reperfusão.

Quatro horas após a reperfusão, os animais foram reanestesiados e submetidos a ventilação mecânica, a artéria carótida foi puncionada para monitoramento da pressão arterial média (PAM) e coleta de sangue para análise de TGO, TGP e TNF-alfa.

Foram coletadas amostras de tecido hepático e pulmonar para análise do malondialdeído (MDA) como índice do stress oxidativo hepático e da atividade da mieloperoxidase (MPO) para avaliar a retenção neutrofílica no pulmão. Os animais foram eutanaziados por exsanguinação.

$2^{\circ}$ lugar Prêmio Painéis - Área Cirurgia no 33 COMU - Congresso Médico Universitário da FMUSP, SP, 31 de out. a 02 de nov. de 2014.

1. Acadêmica de Medicina da Faculdade de Medicina da Universidade de São Paulo.

2. Orientadores, Faculdade de Medicina da Universidade de São Paulo. 


\section{RESULTADOS}

Não houve diferença nos níveis de PAM entre os grupos estudados. Os níveis séricos de TGO e TGP foram significativamente menores nos grupos que sofreram isquemia fria comparado ao grupo Quente.

Os níveis de TNF-alfa foram significativamente menores no grupo Fria comparado ao grupo Quente, e menores nos grupos Fria e Fria-PI comparados ao grupo Fria-PR.

O MDA foi significativamente reduzido no grupo Fria comparado ao grupo Quente, e no grupo Fria-PI comparado aos grupos Fria e Fria-PR. Não houve diferença nos níveis MDA no tecido hepático entre o grupo Fria-PI e o grupo Sham. A MPO diminuiu significativamente nos grupos Fria e Fria-PR comparado ao grupo Fria-PI.

\section{CONCLUSÕES}

A hipotermia hepática reduz as transaminases hepáticas, indicando um aumento da tolerância do fígado à lesão de IR, e diminui os níveis de TNF-alfa, reduzindo a resposta inflamatória da lesão de IR. Além disso, o pré-condicionamento com $\mathrm{SSH}$ do fígado hipotérmico diminui o stress oxidativo, reduzindo ainda mais a lesão de isquemia reperfusão hepática. 